\title{
Comparisons of Streaming Electrification Characteristics between an Ester Liquid and a Mineral Oil using Pipe Flow Method
}

DOI:

10.1109/ICD.2016.7547793

\section{Document Version}

Accepted author manuscript

Link to publication record in Manchester Research Explorer

Citation for published version (APA):

Huang, Y., \& Liu, Q. (2016). Comparisons of Streaming Electrification Characteristics between an Ester Liquid and a Mineral Oil using Pipe Flow Method. In International Conference on Dielectrics 2016 : 03 - 07 July 2016 / France, Montpellier IEEE. https://doi.org/10.1109//CD.2016.7547793

\section{Published in:}

International Conference on Dielectrics 2016

\section{Citing this paper}

Please note that where the full-text provided on Manchester Research Explorer is the Author Accepted Manuscript or Proof version this may differ from the final Published version. If citing, it is advised that you check and use the publisher's definitive version.

\section{General rights}

Copyright and moral rights for the publications made accessible in the Research Explorer are retained by the authors and/or other copyright owners and it is a condition of accessing publications that users recognise and abide by the legal requirements associated with these rights.

\section{Takedown policy}

If you believe that this document breaches copyright please refer to the University of Manchester's Takedown Procedures [http://man.ac.uk/04Y6Bo] or contact uml.scholarlycommunications@manchester.ac.uk providing relevant details, so we can investigate your claim.

\section{OPEN ACCESS}




\title{
Comparisons of Streaming Electrification Characteristics between an Ester Liquid and a Mineral Oil using Pipe Flow Method
}

\author{
Y. M. Huang and Q. Liu* \\ School of Electrical and Electronic Engineering \\ The University of Manchester \\ Manchester M13 9PL, UK \\ *qiang.liu@manchester.ac.uk
}

\begin{abstract}
Streaming electrification has been identified as one of the main failure reasons for large power transformers. Different measurement methods including pipe flow method, rotating disk method and mini-static tester have been proposed to investigate this phenomenon. In this paper, a small scale laboratory based pipe flow model is established. The streaming electrification characteristics of a conventional mineral oil and a synthetic ester liquid were compared. Parameters including flow velocity, pressboard condition and oil aging were studied. The results indicate that the ester liquid exhibits a much higher streaming current than the mineral oil at the investigated flow velocities. Aging of the oil facilitates the charging process in the mineral oil but decreases the streaming current in the ester liquid.
\end{abstract}

Keywords-transformer; streaming electrification; flow electrification; ester, mineral oil

\section{INTRODUCTION}

Transformers play an essential role in the high voltage power systems. Failures of large transformers could pose a significant risk to the power system and consequently induce a high cost to recover. Because of their important role, it is of great significance to avoid insulation breakdowns in transformers.

Generally, two types of insulation materials are used in transformers, i.e. liquid insulation and cellulose based solid insulation. It is known that in transformers, the oil is used not only for insulation but also as a cooling medium. At the liquidsolid interface, an electrical double layer (EDL) is formed. In large oil-filled transformers, the oil is forced to circulate for dissipating the heat generated by the windings [1]. Because of the friction between the solid and the liquid, charge generation occurs at the oil-paper interface [2].

Fig. 1 illustrates the nature of the charge distribution at oilpressboard interface [3]. The first layer is formed by charges of one polarity absorbed tightly at the interface due to chemical interactions, which is called a fixed layer. The second layer is formed by charges of opposite polarity attracted to the surface charges due to Coulomb force. As it is organized more weakly and loosely, it is also called a diffused layer.

In transformers, the oil is electrically neutral when it is at static condition and positively charged when it flows in respect to the solid insulation. Consequently, negative charges are left on the surface of paper/pressboard. Overtime, the charge accumulation will cause increasing DC potential difference across the interface, which may subsequently result in discharges/sparks.

The first transformer failure due to the streaming electrification phenomenon was observed in Japan in 1970s [1] With the increase of rated voltages and capacities of power transformers, oil forced cooling mode is preferred than oil natural cooling mode, which however facilitates the charge generation [4]. Therefore, streaming electrification has been identified as one of the main failure reasons for large power transformers. So far, the phenomenon has been extensively studied [5-8]. Results revealed that the streaming electrification phenomenon can be affected by many factors such as flow velocity, temperature, moisture and aging [6-9].

The conventional mineral oils have dominated the transformer industry for many decades. In recent years, ester liquids have been used as the substitutes for mineral oils due to their high fire point, high moisture tolerance and low environmental impact.

The first synthetic ester filled $400 \mathrm{kV} 240$ MVA transformer is to be connected to UK transmission network. Thus it is significant to study the streaming electrification behaviors of the ester liquids. Up to now, a few publications have revealed that the ester liquids generally have a higher electrostatic charging tendency than the mineral oil [9-11].

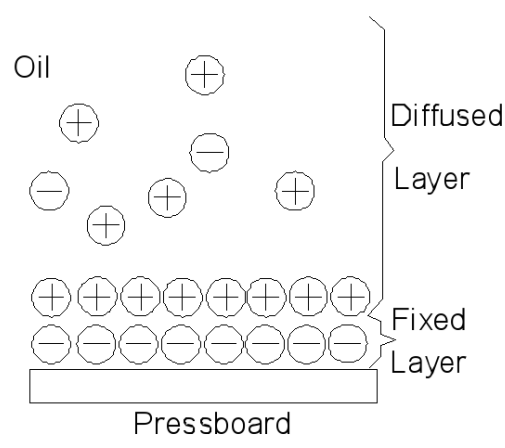

(a)

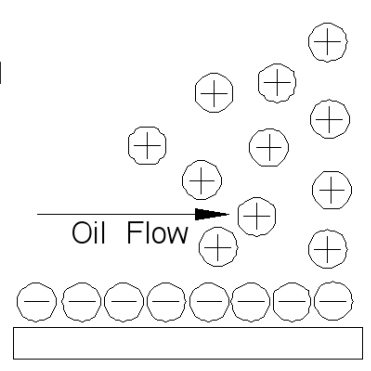

Pressboard

(b)
Fig. 1. Sketch of charge distribution (a) static oil, (b) oil flow 
In this paper, the pipe flow method was employed to study the streaming electrification phenomena. Two types of transformer liquids (a mineral oil, Gemini $\mathrm{X}$ and a synthetic ester, MIDEL 7131) were studied at various flow velocities ranging from $0.021 \mathrm{~m} / \mathrm{s}$ to $0.147 \mathrm{~m} / \mathrm{s}$. The effects of pressboard condition and oil aging on streaming electrification were also investigated.

\section{EXPERIMENTAL SETUP}

\section{A. Experimental Setup}

As shown in Fig. 2 (a), the test rig consists of a pressboard duct, a measuring chamber, a pump, a valve with bypass, a flow meter and a relaxation chamber. The pressboard duct, of which details are shown in Fig. 2 (b), mimics the actual oil duct in a large power transformer. It contains a $280 \mathrm{~mm}$ long pressboard duct where charge separation takes place and a Nylon cover for insulation. Two electrodes made of copper are placed on the top and bottom of the pressboard duct, respectively. These two parallel electrodes are connected for the measurement of the charges accumulated on the pressboard duct.

A volume of 3 liters of insulating liquid is required for testing. The liquid is forced to circulate in the loop by the pump. The flow direction is shown in Fig. 2 (a). Inside the pressboard duct, due to the friction between the liquid and the solid, the charge separation takes place. The negative charges remain on the surface of the pressboard, while the positive charges flow with oil into the measuring chamber. The negative charges accumulated on the pressboard duct can be measured by an electrometer Keithley 6517B. The positive charges leakage from the measuring chamber to the ground can also be measured by the electrometer. The relaxation chamber is placed at upstream of the pressboard duct, which enables extra charges to relax and ensues the oil has become electrically neutral at the inlet of the pressboard duct.

The flow velocity of the oil through the pressboard duct can be obtained via the flow meter and is controlled by the valve with bypass. The whole test rig is placed in a faraday cage for grounding and shielding purposes.

\section{B. Sample Preparations}

Two insulating liquids including a conventional mineral oil Gemini $X$ and a synthetic ester liquid MIDEL 7131 were tested.

Prior to a series of formal experiments, the liquids and pressboards need to be preprocessed. In order to mitigate the influence of impurities, all the oil samples were filtered, degassed and dehydrated before being filled into the system. The mineral oil samples were dehydrated and degassed at 85 ${ }^{\circ} \mathrm{C}$ under a pressure below $500 \mathrm{~Pa}$ for 48 hours. The ester liquid samples were kept in the same condition but for 72 hours. The relative water contents of the oil samples were all reduced to less than $10 \%$. Aged oil samples were also prepared for investigations. 6 liters of preprocessed mineral oil and ester liquid were thermally aged for 7 weeks at $130{ }^{\circ} \mathrm{C}$ in sealed condition. The acidities of the aged mineral oil and the aged ester liquid were $0.159 \mathrm{mg} \cdot \mathrm{KOH} / \mathrm{g}$ and $0.655 \mathrm{mg} \cdot \mathrm{KOH} / \mathrm{g}$, respectively.

All pressboard samples were dehydrated at $105{ }^{\circ} \mathrm{C}$ for 48 hours. In order to investigate the effect of pressboard impregnation, a portion of pressboard samples were further immersed in preprocessed liquids for impregnation. The impregnation process was performed in a vacuum oven under a pressure below $500 \mathrm{~Pa}$ for 48 hours.

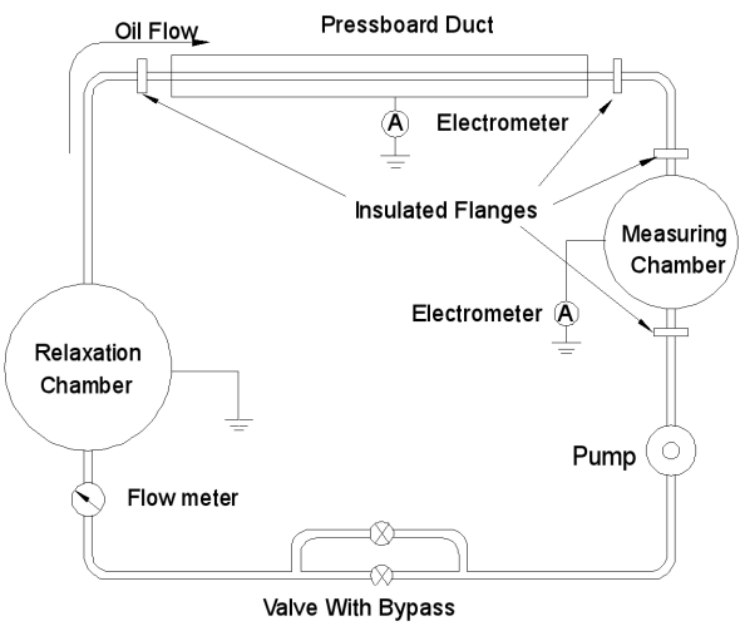

(a)

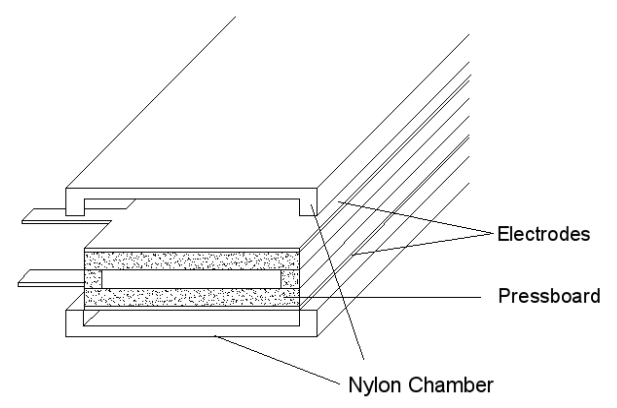

(b)

Fig. 2. Sketch of experimental setup (a) test rig, (b) pressboard duct

\section{Experimental Procedure}

In this paper, six sets of oil/pressboard couples have been studied: unaged mineral oil with dry pressboard, unaged mineral oil with impregnated pressboard, aged mineral oil with impregnated pressboard, unaged ester liquid with dry pressboard, unaged ester liquid with impregnated pressboard and aged ester liquid with impregnated pressboard. According to [12], the oil flow velocity in the winding ducts is from 0.015 $\mathrm{m} / \mathrm{s}$ to $0.156 \mathrm{~m} / \mathrm{s}$ in real transformers. For the tested mineral oil, the flow velocities were set from $0.021 \mathrm{~m} / \mathrm{s}$ to $0.147 \mathrm{~m} / \mathrm{s}$ with an increment of $0.014 \mathrm{~m} / \mathrm{s}$. As the ester liquid has a higher viscosity than the mineral oil, the highest flow velocity for the ester liquid was achieved to be $0.084 \mathrm{~m} / \mathrm{s}$ and the increment was $0.007 \mathrm{~m} / \mathrm{s}$. For each set of oil/pressboard couples, the test was repeated three times for the examination of repeatability. 
A typical waveform of streaming current measured from the measuring chamber is shown in Fig. 3. A typical waveform of leakage current measured from the pressboard duct is shown in Fig. 4. Generally, both leakage current and streaming current would experience a transient state before reaching a steady state. Besides, the two currents have opposite polarities but roughly the same magnitudes. This is because before the charge separation happens, the insulating liquid is electrically neutral. After charges of opposite polarities separate as a result of forced flow motion, the amount of positive charges in the oil should equal to the amount of negative charges accumulated on the pressboard.

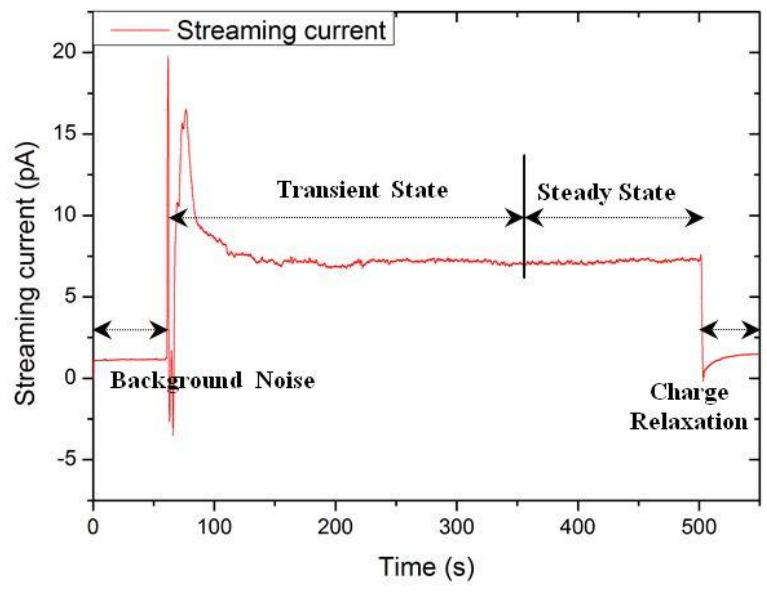

Fig. 3. An example of streaming current waveform

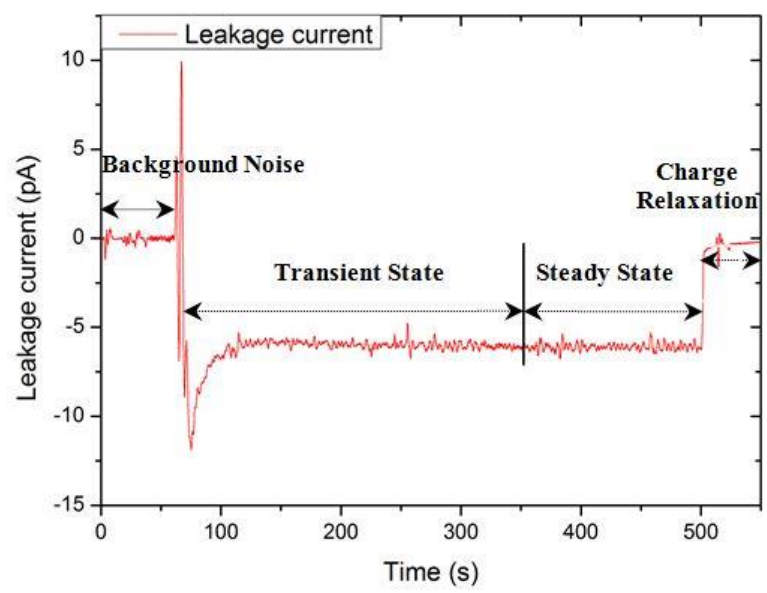

Fig. 4. An example of leakage current waveform

\section{RESULTS AND DISCUSSION}

\section{A. Influence of Flow Velocity}

The measured leakage currents for the mineral oil and the ester liquid under various conditions are summarized in Fig. 5 and Fig. 6. It can be concluded that the leakage current is strongly dependent on flow velocity. As shown in Fig. 5, the leakage current in the mineral oil increases with the increase of flow velocity. Similar findings are also observed in the ester liquid as shown in Fig. 6. The average increase rates of leakage current to flow velocity in different oils with impregnated pressboard are presented in TABLE I. It is obvious that the average increase rate for the mineral oil is much lower than that for the ester liquid.

TABLE I. The average increase rates of leakage current to flow velocity

\begin{tabular}{|c|c|}
\hline Oil Type & Increase Rate $(\mathbf{p A} /(\mathbf{m} / \mathbf{s}))$ \\
\hline Unaged Mineral Oil & 4.41 \\
\hline Aged Mineral Oil & 24.96 \\
\hline Unaged Ester Liquid & 667.23 \\
\hline Aged Ester Liquid & 143.67 \\
\hline
\end{tabular}

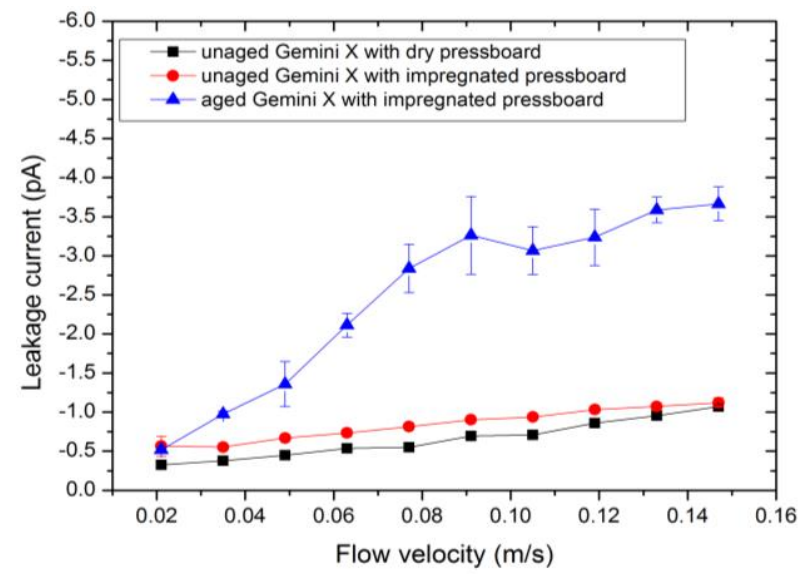

Fig. 5. Leakage currents measured in the mineral oil under different conditions

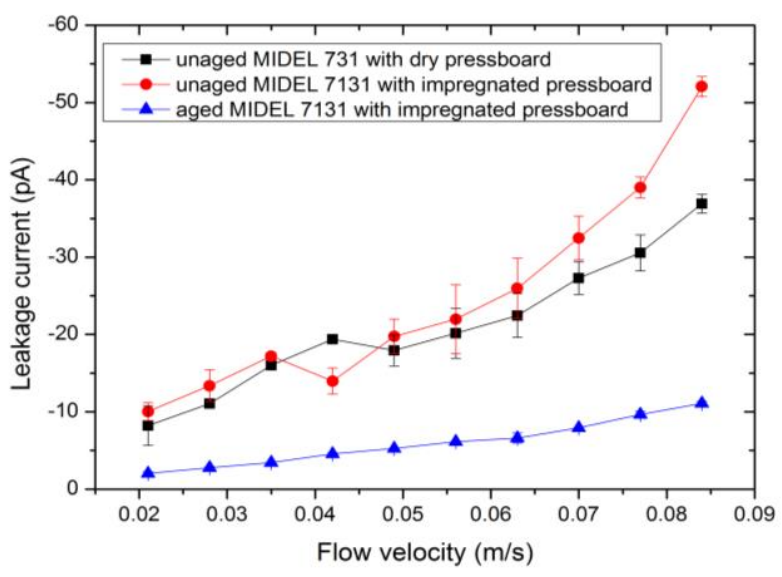

Fig. 6. Leakage currents measured in the ester liquid under different conditions

\section{B. Influence of Pressboard Condition}

As shown in Fig. 5, no significant difference of measured leakage currents can be seen between the unaged mineral oil/dry pressboard couple and the unaged mineral oil/impregnated pressboard couple. However, different results are obtained for the ester liquid. From Fig. 6, it is noticeable 
that the unaged ester liquid/impregnated pressboard couple has a stronger ability to generate leakage current than the unaged ester liquid/dry pressboard couple, especially at higher flow velocity. This difference seems to become larger when flow velocity is further increased.

\section{Influence of Aging}

From Fig. 5 and Fig. 6, it can be found that thermal aging has significant but different influences on the mineral oil and the ester liquid. Fig. 5 shows that the leakage current measured in the aged mineral oil is much higher than that in the unaged mineral oil. In contrast, as shown in Fig. 6, the leakage current from the aged ester liquid is lower than that in the unaged ester liquid.

\section{Comparisons between the Mineral oil and the Ester Liquid}

Fig. 7 compares the leakage current magnitudes between the mineral oil and the ester liquid. It is evident that the ester liquid has a higher leakage current than the mineral oil. Similar findings have also been identified in previous studies [9-11]. The different streaming electrification characteristics of the two liquids have been linked to the differences in the liquids' chemistry [13]. For the mineral oil, thermal aging leads to an increase of leakage current, which agrees with previous findings in [6]. However, it is interesting to observe that the leakage current measured for the ester liquid is decreased after the liquid is thermally aged.

In our previous study [9], a rotating disc method was employed to compare the streaming electrification characteristics between the same mineral oil and ester liquid. In the case of the mineral oil, the aging process increased the streaming current. However, the streaming current magnitudes decreased for the aged ester liquid. The results obtained from previous rotating disk method and the present pipe flow method agree with each other.

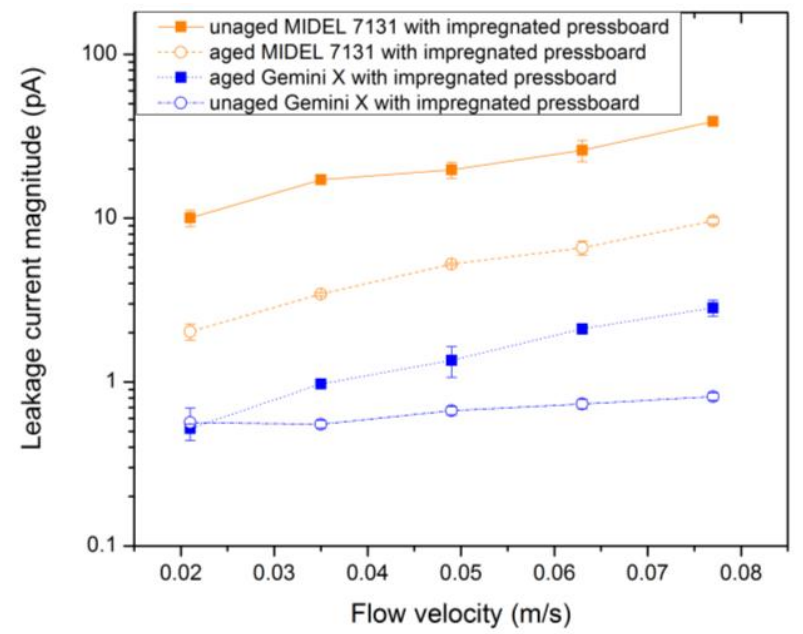

Fig. 7. Comparison of leakage current magnitudes between the mineral oil and the ester liquid at different conditions

\section{CONCLUSIONS}

In this study, a small scale pipe flow model was employed to investigate streaming electrification characteristics of two types of transformer oils including a conventional mineral oil and a synthetic ester liquid.

The results confirm that the streaming electrification is strongly dependent on the oil flow velocity for both the mineral oil and the ester liquid. The increase of flow velocity results in an increase of measured leakage current. Generally, the ester liquid shows a higher ability to generate leakage current than the mineral oil possibly due to its polar nature.

The effects of oil aging on the streaming electrification are however different between the mineral oil and the ester liquid. For the mineral oil, thermal aging facilitates the charge generation process whereas the same ageing process results in reduced leakage current measured in the aged ester liquid, which agrees with our previous findings using the rotating disc method [9].

\section{REFERENCES}

[1] M. Higaki, Y. Kako, M. Moriyama, M. Hirano, K. Hiraishi, and K. Kurita, "Static electrification and partial discharges caused by oil flow in forced oil cooled core type transformers," IEEE Transactions on Power Apparatus and Systems, no. 4, pp. 1259-1267, 1979.

[2] S. Watanabe, N. Hayashi, K. Hayashi, H. Romat, G. Touchard, and A. Richardson, "The streaming electrification phenomenon viewed from the solid-liquid interface." IEEE 11th International Conference on Conduction and Breakdown in Dielectric Liquids (ICDL), pp. 487-491, 1993.

[3] I. Metwally, "Characterization of static electrification in power transformers," IEEE Transactions on Dielectrics and Electrical Insulation, vol. 3, no. 2, pp. 307-315, 1996.

[4] R. Radwan, R. El-Dewieny, and I. Metwally, "Investigation of static electrification phenomenon due to transformer oil flow in electric power apparatus," IEEE Transactions on Electrical Insulation, vol. 27, pp. 278286, 1992

[5] T. Oommen, "Static electrification properties of transformer oil," IEEE Transactions on Electrical Insulation, vol. 23, no. 1, pp. 123-128, 1988.

[6] Ren S, Liu Q, Zhong L, et al. "Electrostatic charging tendency and correlation analysis of mineral insulation oils under thermal aging", IEEE Transactions on Dielectrics and Electrical Insulation, 18(2): 499505, 2011.

[7] T. Oommen, and E. Petrie, "Eelectrostatic Charging Tendency of Transformer Oils," IEEE Transactions on Power Apparatus and Systems, no. 7, pp. 1923-1931, 1984.

[8] G. G. Touchard, T. W. Patzek, and C. J. Radke, "A physicochemical explanation for flow electrification in low-conductivity liquids in contact with a corroding wall," IEEE Transactions on Industry Applications, vol. 32, no. 5, pp. 1051-1057, 1996.

[9] Q. Liu, Z. Liu, and G. Yang, "Comparison of streaming electrification characteristics between an ester liquid and a mineral oil using rotating disc method." IEEE Conference on Electrical Insulation and Dielectric Phenomina (CEIDP), pp. 1026-1029, 2013.

[10] J. Podesser, B. Wieser, M. Muhr, R. Schwarz, G. Pukel, and M. Lashbrook., "Static electrification of different solid-liquid couples used in transformers for insulation." IEEE 18th International Conferecne on Dielectric Liquids (ICDL), pp. 1-4, 2014

[11] M. Zdanowski, "Streaming electrification of mineral insulating oil and synthetic ester MIDEL 7131," IEEE Transactions on Dielectrics and Electrical Insulation, vol. 21, no. 3, pp. 1127-1132, 2014.

[12] J. Zhang, and X. Li, "Coolant flow distribution and pressure loss in ONAN transformer windings. Part II: Optimization of design parameters," IEEE Transactions on Power Delivery,, vol. 19, no. 1, pp. 194-199, 2004.

[13] Y. Zelu, T. Paillat, G. Morin et al., "Study on flow electrification hazards with ester oils." IEEE International Conference on Dielectric Liquids (ICDL), pp. 1-4, 2011 